\title{
QUEEN'S
UNIVERSITY
BELFAST
}

\section{Influence of dielectric layers on performance of transmission mode frequency selective surface based linear to circular polarization}

transformers

Clendinning, S., Cahill, R., Zelenchuk, D., \& Fusco, V. (2020). Influence of dielectric layers on performance of transmission mode frequency selective surface based linear to circular polarization transformers. Microwave and Optical Technology Letters. https://doi.org/10.1002/mop.32238

Published in:

Microwave and Optical Technology Letters

Document Version:

Peer reviewed version

Queen's University Belfast - Research Portal:

Link to publication record in Queen's University Belfast Research Portal

\section{Publisher rights}

@ 2020 Wiley Periodicals, Inc. This work is made available online in accordance with the publisher's policies. Please refer to any applicable terms of use of the publisher.

\section{General rights}

Copyright for the publications made accessible via the Queen's University Belfast Research Portal is retained by the author(s) and / or other copyright owners and it is a condition of accessing these publications that users recognise and abide by the legal requirements associated with these rights.

Take down policy

The Research Portal is Queen's institutional repository that provides access to Queen's research output. Every effort has been made to ensure that content in the Research Portal does not infringe any person's rights, or applicable UK laws. If you discover content in the Research Portal that you believe breaches copyright or violates any law, please contact openaccess@qub.ac.uk. 


\section{Influence of Dielectric Layers on Performance of Transmission Mode FSS Based Linear to Circular Polarization Transformers}

\section{SHORT RUNNING TITLE:}

Clendinnning et al.

\section{AUTHORS:}

Sarah Clendinning, Robert Cahill, Dmitry Zelenchuk and Vincent Fusco

\section{INSTITUTIONAL AFFILIATION:}

The Center for Wireless Innovation (CWI)

The Institute of Electronics, Communications and Information Technology, Queen's University Belfast, Northern Ireland Science Park, Queen's Road, Queen's Island, Belfast BT3 9DT, Northern Ireland, UK

Email: sclendinning01@qub.ac.uk

\section{ACKNOWLEDGEMENTS:}

The first author is supported by a PhD scholarship funded by the Department for the Economy (DfE) Northern Ireland. The authors would also like to thank Mr. Kieran Rainey and Dr. Sasha Malyuskin for their great assistance in the manufacture and measurement of the two structures investigated in this letter. 


\title{
Influence of Dielectric Layers on Performance of Transmission Mode FSS Based Linear to Circular Polarization Transformers
}

\begin{abstract}
In this letter we investigate the electromagnetic behavior of freestanding and dielectric embedded Frequency Selective Surface (FSS) based linear to circular polarization convertors. The two structures were designed to operate in transmission mode at normal incidence and yield the lowest value for axial ratio (AR) at frequencies around $10 \mathrm{GHz}$. In addition to providing mechanical robustness, a $72 \%$ increase in the $3 \mathrm{~dB}$ AR bandwidth (BW) is achieved when the $140 \mu \mathrm{m}$ thick perforated FSS sheet is inserted between two $5 \mathrm{~mm}$ thick PFTE slabs. At oblique incidence a downward shift in frequency is observed, however the bandwidth is still significantly larger than the results obtained for the freestanding periodic array within a field of view (FOV) of $\pm 30^{\circ}$ in the cardinal planes. Spectral transmission measurements presented for both anisotropic media verify the simulated results.
\end{abstract}

Key Words: Frequency Selective Surfaces, circular polarization, linear to circular polarization convertors, periodic structures

\section{INTRODUCTION}

Circularly polarized (CP) waves is the preferred mode of propagation for wireless communication systems, where a rotation of the electric field vector of linearly polarized (LP) waves may lead to a degradation in the link budget [1]. This situation may arise due to Faraday rotation or polarization mismatch occurring when the transmit and receive antennas are not precisely aligned. In addition to removing this source of signal loss, $\mathrm{CP}$ wave propagation can reduce fading that is attributed to multipath scattering. However $\mathrm{CP}$ waveforms are more difficult to generate because the vertical and horizontal plane wave components must satisfy precise amplitude and phase criteria to achieve the desired polarization purity [1]. One approach for generating CP signals is through the integration of a standalone polarization convertor and a linearly polarized source antenna. Frequency Selective Surfaces 
(FSS) that exhibit anisotropic wave impedances [2] are commonly used for this purpose, working in either reflection mode [3] or transmission mode [4-19]. The latter class of LP to CP polarization convertors are composed of an array of printed metallic elements or asymmetric shaped slots formed in a thin metal sheet. These arrays can be used individually or cascaded to increase the AR bandwidth and reduce the insertion loss. As an alternative to the more bulky and more complex multi-layered design options reported in [4-9], several single sheet topologies have been studied [10-19]. For example in [11] the authors described the design of a metasurface with unit cells composed of a printed metal annular ring in which a rectangular strip is embedded. This structure exhibits a $3 \mathrm{~dB}$ AR BW of $17 \%$ centered at $14.4 \mathrm{GHz}$. More recently Fei et al. showed that bandwidths exceeding $47 \%$ are obtainable from centrosymmetric dual-loop elements [12] and hybrid meander line and loop configurations [13].

In this paper we investigate the electromagnetic behaviour of LP to CP polarization convertors based on aperture (slot) FSS. These strongly reject incident signals at frequencies above and below the spectral passband and therefore have the ability to provide self-filtering of incident waves [20], [21]. As a general observation, the signal transmission is much lower outside of the operating frequency band than the single sheet topologies reported in [10-19]. Moreover unlike printed arrangements, radar crossection reduction can be achieved by printing a resistively loaded FSS (such as the one presented in [22]) on the outermost surface of a dielectric spacer to create a microwave absorber out of band. These structures are inherently narrowband, but by careful choice of the slot width, metal thickness and periodicity, the authors have recently shown that the $3 \mathrm{~dB}$ axial ratio bandwidth of a single layer LP to CP polarization convertor can be increased from $2.4 \%$ reported in [14] to $5.0 \%$ [15] at normal incidence. In [16] and [17] the plane wave transmission response of a FSS filter was shaped by inserting an array of linear slots between two dielectric layers. This observation was used in [18] to create an innovative cross-slot polarization convertor design, which exhibits an AR BW of 7.9\% working at normal incidence.

The purpose of this letter is to evaluate the electromagnetic performance of single layer freestanding and dielectric embedded aperture FSS screens, when these are illuminated by LP plane waves over a field of view (FOV) $\pm 15^{\circ}$ and $\pm 30^{\circ}$ in the cardinal planes. The two LP to CP polarisation convertors were designed to work at normal incidence and achieve the maximum possible $3 \mathrm{~dB}$ AR BW centered 
at a frequency around $10 \mathrm{GHz}$ [15], [18]. At oblique incidence the axial ratio minimum shifts to a lower frequency, thus reducing the bandwidth for oblique incidence operation and for each of the two FOV cases studied. However, the numerical simulations and experimental results show that the dielectric clad polarisation convertor gives a significantly improved performance, and is a better option for reducing the degradation attributed to angular sensitivity.

\section{PRINCIPLE OF OPERATION}

When orthogonal LP signals are concurrently transmitted from a source, the resultant wave is said to be perfectly circularly polarized when the amplitude of the signals are the same and the two waves are in phase quadrature [1]. Freestanding FSS composed of thin metal perforated arrays of unequal length cross slots can be designed to produce such signals by careful selection of the unit cell geometry and physical dimensions. The individual coupled slots resonate at a frequency that is determined by the length of the aperture element. At resonance the FSS is impedance matched to free space (377 $\Omega$ ) and the signal transmits with low loss if the conductivity of the sheet is similar to commonly used bulk metals. Signals at frequencies slightly above or below resonance will experience either a capacitive or an inductive environment and will be transmitted with a phase advance or delay respectively. Therefore, by constructing an FSS with unit cells composed of dissimilar length orthogonal slots, and illuminating the structure with slant $45^{\circ}$ incident waves, a perfect $\mathrm{CP}$ wave can be transmitted at the center design frequency. The spectral response of the transmitted signals can be varied by changing the unit cell geometry and the inherent $3 \mathrm{~dB}$ loss can be reduced significantly by cascading two identical freestanding screens [14]. The topology of the single layer freestanding LP to CP polarization convertor which is reported in this paper was optimized for maximum AR BW using guidelines given in [15]. An additional degree of freedom is exploited in the design to further increase the AR BW of the transmitted waves by deploying dielectric layers to tailor the amplitude and phase response of the TE and TM waves [18]. A schematic of the freestanding and embedded unit cells are presented in Fig. 1 (a) and (b) respectively. 


\section{NORMAL AND OBLIQUE ANGLE RESPONSE}

In this letter we evaluate and compare the electromagnetic behavior of a freestanding FSS based LP to $\mathrm{CP}$ polarization convertor with a periodic structure that is encased between two $5 \mathrm{~mm}$ thick $\operatorname{PTFE}\left(\varepsilon_{\mathrm{r}}=\right.$ 2.1) layers. The purpose of the study is to establish the impact of angular sensitivity on the bandwidth and polarization purity of the transmitted CP waves. CST Microwave Studio was used to simulate the spectral responses of the two structures working at an angle of incidence of $0^{\circ}, 15^{\circ}$ and $30^{\circ}$ in two cardinal planes. The two FSS arrays were modelled by forming the cross slots in a $140 \mu \mathrm{m}$ thick metalized PET sheet $\left(\varepsilon_{\mathrm{r}}=2.95, \tan \delta=0.025\right)$, to replicate the ink jet manufacturing technique which is described in section 4. Periodic boundary conditions were applied to compute the spectral transmission in the TE and TM planes using a single $3 \mathrm{D}$ unit cell. The $\mathrm{S}_{21}$ responses were post processed in MATLAB using equations given in [1] to obtain the AR values at each frequency. Table 1 summarizes the unit cell dimensions for each of the two optimized structures, which were designed for normal incidence operation [15], [18]. In the numerical model the E vector of the impinging LP wave is orientated at an angle of $45^{\circ}$ with respect to the $\mathrm{XY}$ axes depicted in Fig. 1 (a). The angle of the incident plane waves was varied from $\theta=0^{\circ}$ to $30^{\circ}$ and simulations were performed in the two cardinal cuts, parallel to the direction of the two slot arms. In Fig. 1 (a) these are defined as the $\varphi=0^{\circ}(\mathrm{XZ})$ and $\varphi=90^{\circ}$ (YZ) planes. For brevity, the TE and TM spectral transmission responses are only illustrated for normal incidence operation in Fig. 2 (a) and (b). The dielectric embedded structure exhibits a smaller amplitude difference and a slower variation from phase quadrature above and below the crossover (operating) frequency at which the criteria for perfect CP signal generation is obtained. This is highlighted in Fig. 2 (c), and is the reason why the AR bandwidth is larger than the value obtained for the LP to CP convertor based on the freestanding FSS. The influence of the two dielectric slabs can also be illustrated by employing the equivalent circuit model (ECM) shown in Fig. 3 (a) to compute the electromagnetic behaviour of the structure. The parallel LC circuit is used to model the cross slot FSS and the impact of the dielectric slabs is accounted for by inserting two transmission lines of impedance $Z_{t}=260 \Omega$ $\left(\mathrm{Z}_{0} / \sqrt{\varepsilon_{\mathrm{r}}}\right)$. Using the same method discussed in [19], the LC values were extracted and as shown in Fig. 3 (b), an inductance of $\mathrm{L}=0.41 / 1.66 \mathrm{nH}$ and capacitance $\mathrm{C}=0.42 / 0.32 \mathrm{pF}(\mathrm{TE} / \mathrm{TM})$ provides an excellent fit to the full wave simulations in the crossover region, when the $\mathrm{S}_{21}$ parameters are calculated 
using the ECM. As a general observation, far outside the operating frequency range for frequencies above $12.6 \mathrm{GHz}(\mathrm{TE})$ and below $8.1 \mathrm{GHz}(\mathrm{TM})$, the results obtained from the ECM are shown to deviate from the full wave model. Fig. 3 (b) also shows that by removing the two transmission lines in the ECM and hence the effect of the dielectric slabs, an undesirable increase in the Q factor of the $\left|S_{21}\right|$ responses occurs. Moreover, at the crossover point, $10.3 \mathrm{GHz}$, the computed phase difference between the TE and TM waves is $129^{\circ}$ resulting in a minimum AR of $6.3 \mathrm{~dB}$.

(i) $\varphi=0^{\circ}$ cut: At normal incidence the $3 \mathrm{~dB}$ AR bandwidth of the freestanding (Fig. 4 (a)) and dielectric embedded (Fig. 4 (b)) polarization convertors are $4.6 \%$ and $7.9 \%$ respectively. Fig. 4 shows that as $\theta$ increases from $0^{\circ}$ to $30^{\circ}$, a downward shift in the center operating frequency from $10 / 10.3 \mathrm{GHz}$ to $9.7 / 9.8$ $\mathrm{GHz}$ is predicted, in conjunction with an increase in the minimum axial ratio from $0.1 / 0.2 \mathrm{~dB}$ to $2.0 / 0.4$ dB.

(ii) $\varphi=90^{\circ}$ cut: For this case the predicted shift in the center working frequency varies from $10 / 10.3$ $\mathrm{GHz}$ to $9.5 / 9.9 \mathrm{GHz}$ for a wave impinging at $0^{\circ}$ and $30^{\circ}$ incidence on the freestanding (Fig. 5(a)) and embedded (Fig. 5(b)) surfaces. Moreover the polarization purity is degraded and Fig. 5 shows that the minimum axial ratio value is predicted to increase from $0.1 / 0.2 \mathrm{~dB}$ to $3.8 / 1.4 \mathrm{~dB}$.

(iii) Summary of Results: The numerical results depicted in Fig. 4 and 5 clearly show the influence of changing angle of incidence on the transmission properties of the two polarization convertors. The polarization purity at the center frequency for normal incidence operation is degraded by the downward frequency shift of the AR response curves, and for one arrangement with plane waves incident at $\theta=$ $30^{\circ}$, and $\varphi=90^{\circ}$, the freestanding screen exhibits a minimum $\mathrm{AR}$ value that exceeds $3 \mathrm{~dB}$ and is not included in the summary. In general, for oblique incidence operation, the two LP to CP structures yield narrower frequency offset bandwidths, but by sandwiching the periodic array between two identical PTFE slabs a significantly larger value is obtained. The numerical results are summarized in Table 2, where the frequency $\left(f_{0}\right)$ given for each tilt angle studied, corresponds to the center of the band over which the AR is less than $3 \mathrm{~dB}$. The superior angular stability that is exhibited by the dielectric embedded LP to CP polarization convertor is further demonstrated in the two cardinal planes by 
observing the common $3 \mathrm{~dB}$ AR bandwidth, which is obtained in the FOV of $\pm 15^{\circ}$ and $\pm 30^{\circ}$. The results are given in Table 3.

\section{FABRICATION AND EXPERIMENTAL RESULTS}

The two FSS based LP to CP polarization transformers were manufactured by ink-jet printing the slots on a $140 \mu \mathrm{m}$ thick Novele IJ-220 PET sheet [23] using an Epson Stylus C88+ printer and Metalon JSB25HV silver ink [24]. After printing, the FSS was placed in an oven to cure at a temperature of $90^{\circ} \mathrm{C}$ for approximately 20 minutes. The freestanding perforated screen was mounted on a flat $12 \mathrm{~mm}$ thick Rohacell foam sheet with an aluminum tape rim. For the embedded structure 3M Spray Mount [25] was used to bond the printed PET sheet to the surfaces of the $5 \mathrm{~mm}$ thick PTFE slabs as shown in Fig. 6 . Pressure was applied to the completed structure during the manufacturing process as a means to remove air gaps.

Measurements were conducted in an anechoic environment using a $91 \mathrm{~cm}$ x $91 \mathrm{~cm}$ screen covered with radar absorbent material (RAM). A $30 \mathrm{~cm}$ x $30 \mathrm{~cm}$ aperture was inserted in the center of the screen to support the two polarization convertors. The structures were placed between two standard gain horns which were separated by a distance of $122 \mathrm{~cm}$, and carefully aligned with the FSS using a Tacklife SCLO3 laser [26]. The $\mathrm{S}_{21}$ measurements were made using an Agilent PNA 8631A which was connected to the two antennas. The transmit horn was rotated about its propagation axis to produce an impinging slant $45^{\circ}$ signal and the receive horn was orientated at $0^{\circ}$ and $90^{\circ}$ in order to record the amplitude and phase of the TE and TM waves. The receiver horn was mounted onto a NSI 2000 planar nearfield scanner, [27], which allowed for automated alignment and rotation of the horn. The RAM covered support stand was fixed on an azimuth turntable, in order to rotate the structure from $0^{\circ}$ to $90^{\circ}$ about the Y-axis (Fig. 1). Both the FSS and the two feed horns were rotated by $90^{\circ}$ to enable measurements to be made in the $\varphi=90^{\circ}$ plane. Fig. 7 shows a photograph of the experimental set-up with the receive horn orientated for a TM measurement.

Plane wave incidence is assumed in the CST model, however measurements made using the NSI vertical planar scanner show that for this test set-up, there is an amplitude (phase) variation of $\pm 1.0 \mathrm{~dB}\left( \pm 80^{\circ}\right)$ 
over the $2 \mathrm{D}(19 \mathrm{~cm} \times 27 \mathrm{~cm})$ surface of the FSS. However in general the results plotted in Fig. 4 and 5 and summarized in Table 2 are in reasonably good agreement with the full-wave simulations for the free standing anisotropic FSS. Similarly the much larger AR BW obtained at all angles for the PTFE embedded LP to CP convertor is verified experimentally, but an upward frequency shift is observed in the position of the AR minimum, for example by $8.7 \%$ at normal incidence. This deviation from the simulated results is mainly attributed to air voids between the two dielectric sheets which encase the slots. Our computations show that a $0.28 \mathrm{~mm}$ airgap, which can easily be attributed to the surface roughness of the PTFE slabs, is sufficient to shift the operating frequency from $10.3 \mathrm{GHz}$ to $11.2 \mathrm{GHz}$ (Fig. 8), which is similar to the result observed at normal incidence $(11.1 \mathrm{GHz})$. The numerical results shown in Table 3 for the two field of view values are verified experimentally. These demonstrate that the freestanding LP to CP polarization convertor exhibits a much smaller AR BW for FOV $\pm 15^{\circ}$, but as a consequence of the larger than predicted shift in the frequency of the AR minimum for the $30^{\circ}$ tilt angle measurements in both planes, no common $3 \mathrm{~dB}$ AR bandwidth could be measured for the two structures. As a general observation, the discrepancies between the numerical and experimental results that were found for some of the minimum AR values, are mainly attributed to variations between the measured and simulated phase difference between the TE and TM waves at the frequency where the amplitude crossover occurs. To illustrate the performance sensitivity relating to the phase differences between the two waves, consider an example where the dielectric embedded FSS is illuminated at $\varphi=$ $90^{\circ}$ and $\theta=30^{\circ}$. For this case, a phase difference of $74^{\circ}$ and an AR minimum of $2.8 \mathrm{~dB}$ was measured at $10.4 \mathrm{GHz}$, whereas the computed result gives a phase difference of $82^{\circ}$ and an AR minimum of 1.4 dB at $9.9 \mathrm{GHz}$.

\section{CONCLUSIONS}

In this letter we have investigated and compared the electromagnetic performance of two different FSS based LP to CP polarization convertors working over a range of angles $0^{\circ}$ to $30^{\circ}$ in orthogonal planes of incidence. By deploying two $5 \mathrm{~mm}$ thick PTFE supporting layers to weaken the amplitude roll-off above resonance in conjunction with reducing the phase gradient exhibited by the transmitted TE and TM waves (Fig. 2 (c)), we have shown that the AR bandwidth can be increased, by up to $72 \%\left(\theta=0^{\circ}\right)$, 
$100 \%\left(\theta=15^{\circ}, \varphi=90^{\circ}\right)$, and $85 \%\left(\theta=30^{\circ}, \varphi=0^{\circ}\right)$ working at each of the three individual angles investigated. Moreover this improved and more robust architecture achieves much better angular stability over a FOV of $\pm 15^{\circ}$ and $\pm 30^{\circ}$ with an increase in the AR BW of up to $128 \%\left(\varphi=90^{\circ}\right)$ and $150 \%\left(\varphi=0^{\circ}\right)$ respectively. The trends observed from the numerical simulations are in reasonably good agreement with results that were obtained from measuring the spectral transmission of the periodic arrays which were manufactured by using an ink-jet printer to pattern the FSS. The improved design reported in this letter can be used as a building block to create a multilayer dielectric embedded LP to CP polarization convertor with two or more FSS sheets. This could potentially reduce the loss [14] and further increase the AR bandwidth and angular stability. 


\section{REFERENCES}

1. Toh B Y, Cahill R, Fusco V F. Understanding and measuring circular polarisation. IEEE Transactions on Education, 2003; 46(3):313-319.

2. Biniti $\mathrm{S}$, Cahill $\mathrm{R}$ and Schuchinsky A. Polarization independent resistively loaded FSS absorber with optimum oblique incident performance. Proc. IET Microwaves Antennas and Propagation, 2014; 8(14): 1198-1203.

3. Perez-Palomino G, Page J E, Arrebola M, and Encinar J. A design technique based on equivalent circuit and coupler theory for broadband linear to circular polarization convertors in reflection or transmission mode. IEEE Transactions on Antennas and Propagation, 2018; 66(5): 2428-2438.

4. Naseri P, Matos S, Costa J, Fernandes C, and Fonseca N. Dual-band dual-linear-to-circular polarization convertor in transmission mode application to $\mathrm{K} / \mathrm{Ka}$-band satellite communications. IEEE Transactions on Antennas and Propagation, 2018; 66(12):71287137.

5. Hosseini M, Hum S. A circuit driven design methodology for a circular polarizer based on modified Jerusalem cross grids. Proc IEEE Antennas and Propagation, 2017; 65: 53225331.

6. Blanco D and Sauleau R. Broadband and broad-angle multilayer polarizer based on hybrid optimisation algorithm for low-cost Ka-band applications. Proc IEEE Antennas and Propagation, 2018; 66(4): 1874-1881.

7. Lerner, D. A wave polarization converter for circular polarization. IEEE Transactions on Antennas and Propagation, 1965, 13(1): 3-7.

8. Baoqin $\mathrm{L}, \mathrm{Wu} \mathrm{J}, \mathrm{Da} \mathrm{X}, \mathrm{Li} \mathrm{W}$, and Ma J. A linear-to-circular polarization converter based on a second-order band-pass frequency selective surface. Applied Physics A, 2017; 123(1):43.

9. Mahdi F, and Armaki S. Design of metasurface polarization converter for near-field application; stacked conical horn antenna for circular polarization. International Journal of $R F$ and Microwave Computer-Aided Engineering, 2019; 29(7): 21712.

10. Baena J, Glybovski S, Risco J, Slobozhanyuk A, and Belov P. Broadband and thin linear to circular polarisers based on self-complementary zigzag metasurfaces. Proc IEEE Antennas and Propagation, 2017; 65(8): 4123-4133.

11. Xiaoliang $\mathrm{M}$, Huang $\mathrm{C}, \mathrm{Pu} \mathrm{M}, \mathrm{Hu} \mathrm{C}$, Feng Q, and Luo X. Single-layer circular polarizer using metamaterial and its application in antenna. Microwave and Optical Technology Letters, 2012; 54(7): 1770-1774.

12. Fei $\mathrm{P}, \mathrm{Hu} \mathrm{W}$, Guo W, and Wen X. Design of a Wideband Planar Linear-Circular Polarization Converter with Centrosymmetric Dual-Loop Elements. Progress In Electromagnetics Research, 2018; 74: 83-92.

13. Fei $P$, Shen $Z$, Wen $X$, and Nian F. A single-layer circular polarizer based on hybrid meander line and loop configuration. IEEE Transactions on Antennas and Propagation, 2015; 63(10): 4609-4614.

14. Euler M, Fusco VF, Cahill R and Dickie R. Comparison of FSS based linear to circular polarization convertor geometries. Proc. IET Microwaves Antennas and Propagation, 2010; 4(11): $1764-1772$.

15. Clendinning S, Cahill R, Zelenchuk D, and Fusco V. Bandwidth optimization of linear to circular polarization convertors based on slot FSS. Microwave and Optical Technology Letters, 2019; 61(5): 1200-1207. 
16. Callaghan P, Parker E A, and Langley R J. Influence of supporting dielectric layers on the transmission properties of frequency selective surfaces. IEE Proc. Microwaves, Antennas and Propagation, 1991;138(5): 448-454.

17. B.A. Munk, Frequency Selective Surfaces Theory and Design. New York: Wiley, 2000.

18. Clendinning S, Cahill R, Zelenchuk D, and Fusco V. Dielectric embedded bandpass FSS linear to circular polarisation transformers. Proc. European Conference Antennas and Propagation. Krakow, April 2019.

19. Clendinning S, Cahill R, Zelenchuk D, and Fusco V. Equivalent circuit model for linear to circular polarisation convertors based on bandpass FSS screens. Loughborogh Antennas and Propagation Conference. Loughborogh, November 2018.

20. Farzami F, Khaledian S, Smida B and Erricolo D. Reconfigurable linear/circular polarization rectangular waveguide filtenna. Proc IEEE Antennas and Propagation, 2018; 66(1):9- 15.

21. Barbuto M, Trotta F, Bilotti F and Toscano A. A combined Bandpass filter and polarization transformer for horn antennas. IEEE Antennas and Wireless Propagation Letters, 2013; 12 : 1065-1068.

22. Biniti S, Cahill R and Schuchinsky A. Compact FSS absorber design using resistively loaded quadruple hexagonal loops for bandwidth enhancement. IET Electron. Lett. 2015; 51(2): 162164.

23. Novacentrix. Novele IJ-220,2212. Available at :www.novacentrix.com. Accessed August 13 2019.

24. Novacentrix. Metalon JS-B25HV,2011. Available at :www.novacentrix.com/products/metalon-conductive-inks. Accessed August 132019.

25. 3M. 3M SprayMount $400 \mathrm{ml}$ Can. Available at: https://www.3m.co.uk/3M/en_GB/scotcheu/products/catalog/ /3M-SprayMount-400-ml-

$\mathrm{Can} / \mathrm{P}=5002385+8709316+8709380+8710660+8710918+8711729+8712974+8736248+3$ $294174673 \& \mathrm{rt}=$ rud. Accessed August 132019.

26. Amazon. Laser level tacklife SC-L03-98ft crossline self-leveling - 360-degree horizontal line-magnetic pivoting base, carrying pouch, $2 x$ pulse modes, battery included. Available at: https://www.amazon.com/98ft-Crossline-Self-Leveling-Laser-Level/dp/B07H3P8H8B. Accessed August 132019.

27. NSI MI. NSI2000 professional edition. Available at: https://www.nsimi.com/products/software-products/nsi2000-professional-edition-upgrade. Accessed August 132019. 


\section{TABLES}

Table 1. Dimensions of the unit cells used to construct the freestanding and dielectric embedded LP to CP convertors.

\begin{tabular}{r|ll}
\hline Dimension & $\begin{array}{l}\text { Freestanding [6] } \\
(\mathbf{m m})\end{array}$ & $\begin{array}{l}\text { Embedded [9] } \\
(\mathbf{m m})\end{array}$ \\
\hline$d x$ & 19.2 & 14.0 \\
$d y$ & 19.2 & 14.0 \\
$w$ & 4.1 & 2.7 \\
$l x$ & 12.95 & 8.51 \\
$l y$ & 18.7 & 13.9 \\
$t$ & $\mathrm{~N} / \mathrm{A}$ & 5.0 \\
\hline
\end{tabular}

Table 2. Summary of simulated and measured results for normal and oblique incidence operation. Measured results are shown in brackets.

\begin{tabular}{|c|c|c|c|c|c|}
\hline Scan Plane & Structure & Angle & $3 d B A R B W$ & $\begin{array}{c}f_{0} \\
(G H z)\end{array}$ & $\begin{array}{c}\operatorname{Min} A R \\
(d B)\end{array}$ \\
\hline & Freestanding & $0^{\circ}$ & $\begin{array}{c}4.6 \% \\
(5.2 \%)\end{array}$ & $\begin{array}{c}10.0 \\
(10.0)\end{array}$ & $\begin{array}{c}0.1 \\
(1.3 / 0.8)\end{array}$ \\
\hline & Embedded & $0^{\circ}$ & $\begin{array}{c}7.9 \% \\
(9.6 \%) \\
\end{array}$ & $\begin{array}{c}10.3 \\
(11.1) \\
\end{array}$ & $\begin{array}{c}0.2 \\
(0.8 / 0.0) \\
\end{array}$ \\
\hline \multirow[t]{4}{*}{$\varphi=0^{\circ}$} & Freestanding & $15^{\circ}$ & $\begin{array}{c}4.6 \% \\
(5.5 \%)\end{array}$ & $\begin{array}{c}9.9 \\
(9.9)\end{array}$ & $\begin{array}{c}0.5 \\
(1.1)\end{array}$ \\
\hline & & $30^{\circ}$ & $\begin{array}{c}3.4 \% \\
(4.5 \%)\end{array}$ & $\begin{array}{c}9.7 \\
(9.5)\end{array}$ & $\begin{array}{c}2.0 \\
(1.0)\end{array}$ \\
\hline & Embedded & $15^{\circ}$ & $\begin{array}{c}8.0 \% \\
(9.6 \%)\end{array}$ & $\begin{array}{c}10.2 \\
(10.7)\end{array}$ & $\begin{array}{c}0.2 \\
(0.8)\end{array}$ \\
\hline & & $30^{\circ}$ & $\begin{array}{c}6.3 \% \\
(10.6 \%) \\
\end{array}$ & $\begin{array}{c}9.8 \\
(9.9) \\
\end{array}$ & $\begin{array}{c}0.4 \\
(1.6) \\
\end{array}$ \\
\hline \multirow[t]{4}{*}{$\varphi=90^{\circ}$} & Freestanding & $15^{\circ}$ & $\begin{array}{c}3.5 \% \\
(4.4 \%)\end{array}$ & $\begin{array}{c}9.9 \\
(9.9)\end{array}$ & $\begin{array}{c}1.1 \\
(1.4)\end{array}$ \\
\hline & & $30^{\circ}$ & $\begin{array}{l}- \\
(-)\end{array}$ & $\begin{array}{l}- \\
(-)\end{array}$ & $\begin{array}{c}3.8 \\
(5.5)\end{array}$ \\
\hline & Embedded & $15^{\circ}$ & $\begin{array}{c}7.0 \% \\
(8.0 \%)\end{array}$ & $\begin{array}{c}10.2 \\
(11.0)\end{array}$ & $\begin{array}{c}0.5 \\
(0.9)\end{array}$ \\
\hline & & $30^{\circ}$ & $\begin{array}{c}5.1 \% \\
(2.6 \%) \\
\end{array}$ & $\begin{array}{c}9.9 \\
(10.4) \\
\end{array}$ & $\begin{array}{c}1.4 \\
(2.8) \\
\end{array}$ \\
\hline
\end{tabular}


Table 3. Summary of simulated and measured results for field of view (FOV) $\pm 15^{\circ}$ and $\pm 30^{\circ}$.

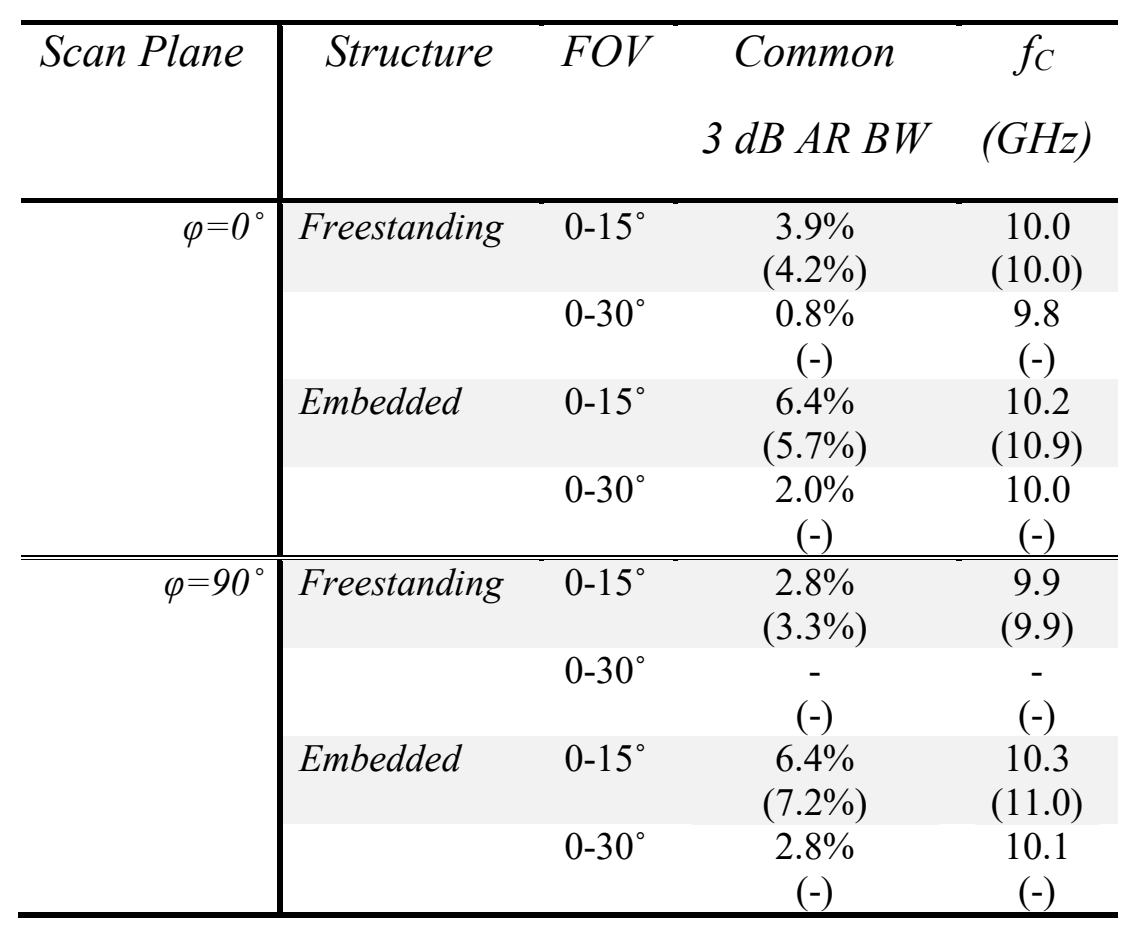


Figure 1. Schematic of a unit cell (a) freestanding FSS and (b) FSS embedded between two PTFE slabs, each of thickness $t$.

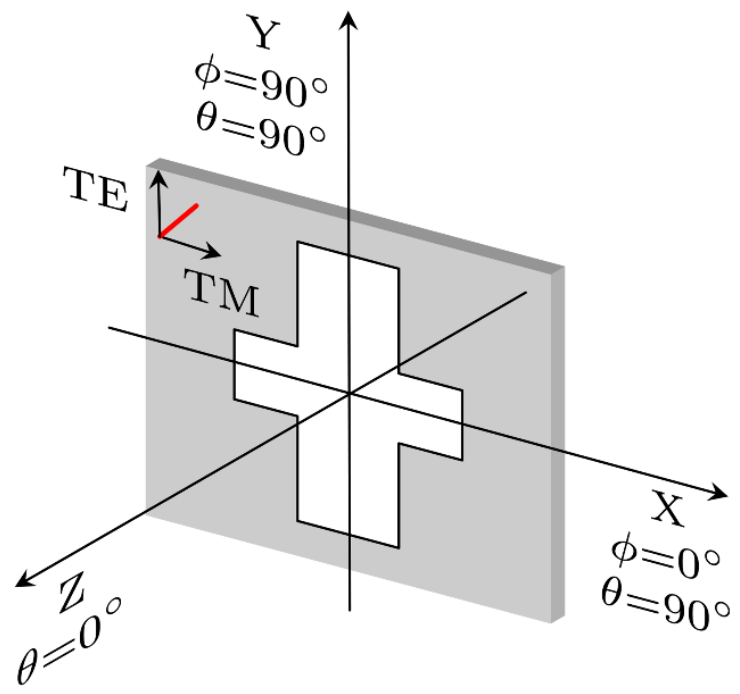

(a)

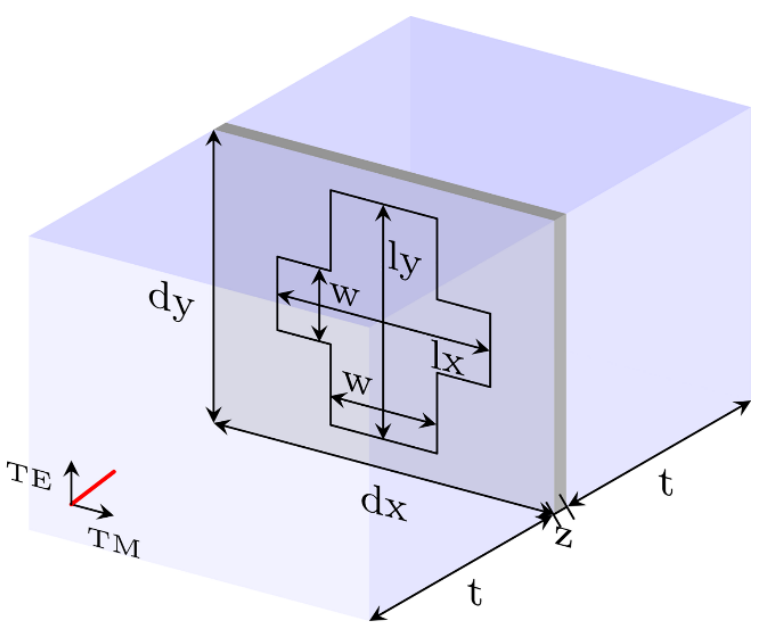

(b) 
Figure 2. Computed transmission responses at normal incidence (a) amplitude, (b) phase, (c) TE and TM plane amplitude and phase differences.

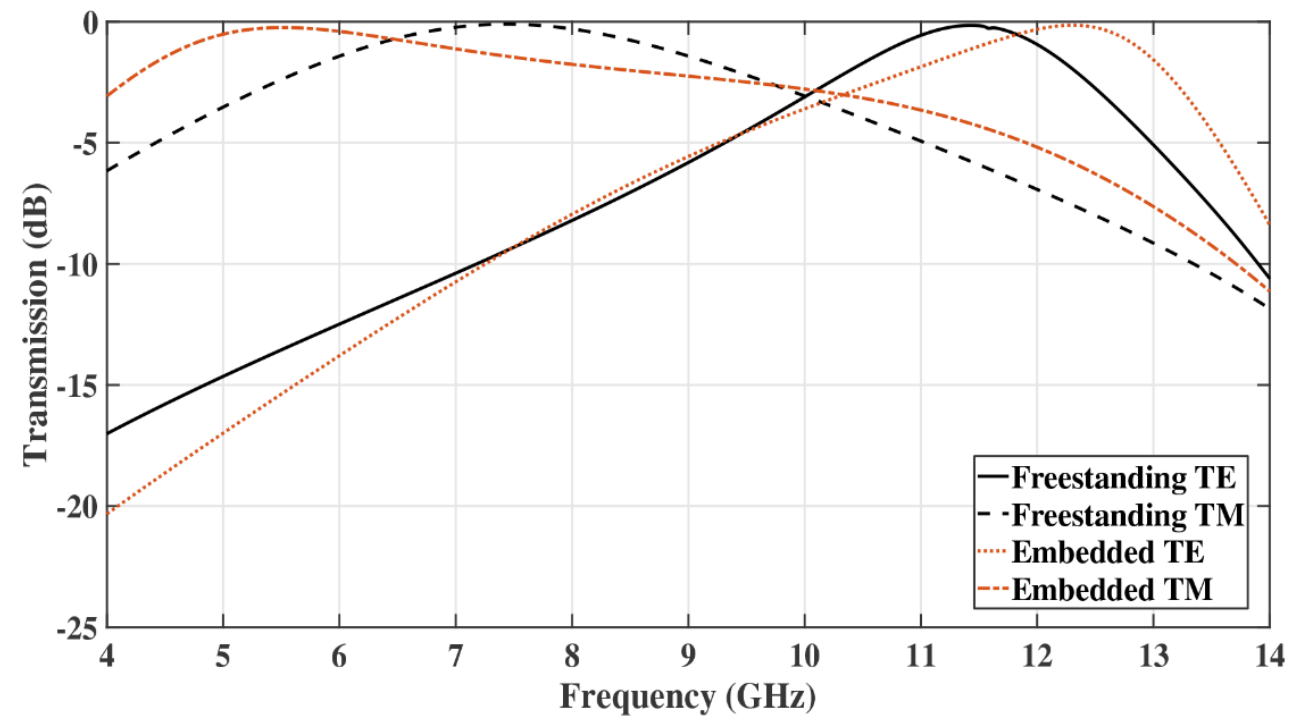

(a)

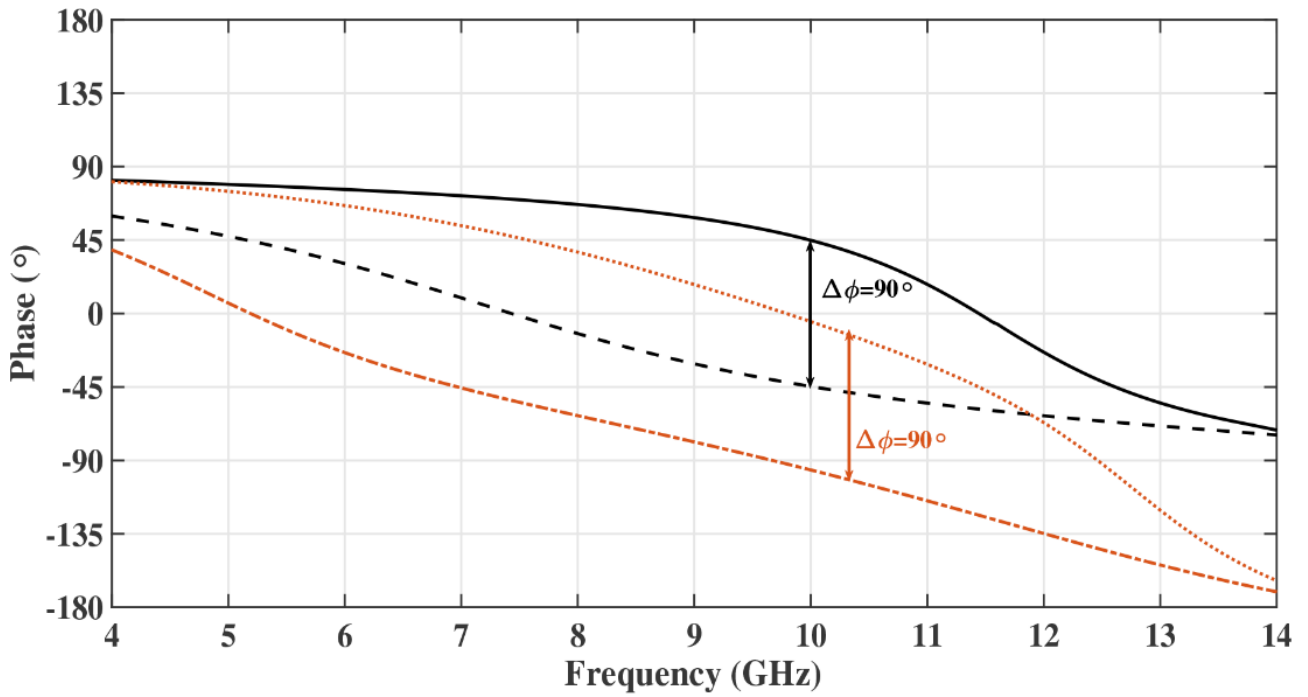

(b)

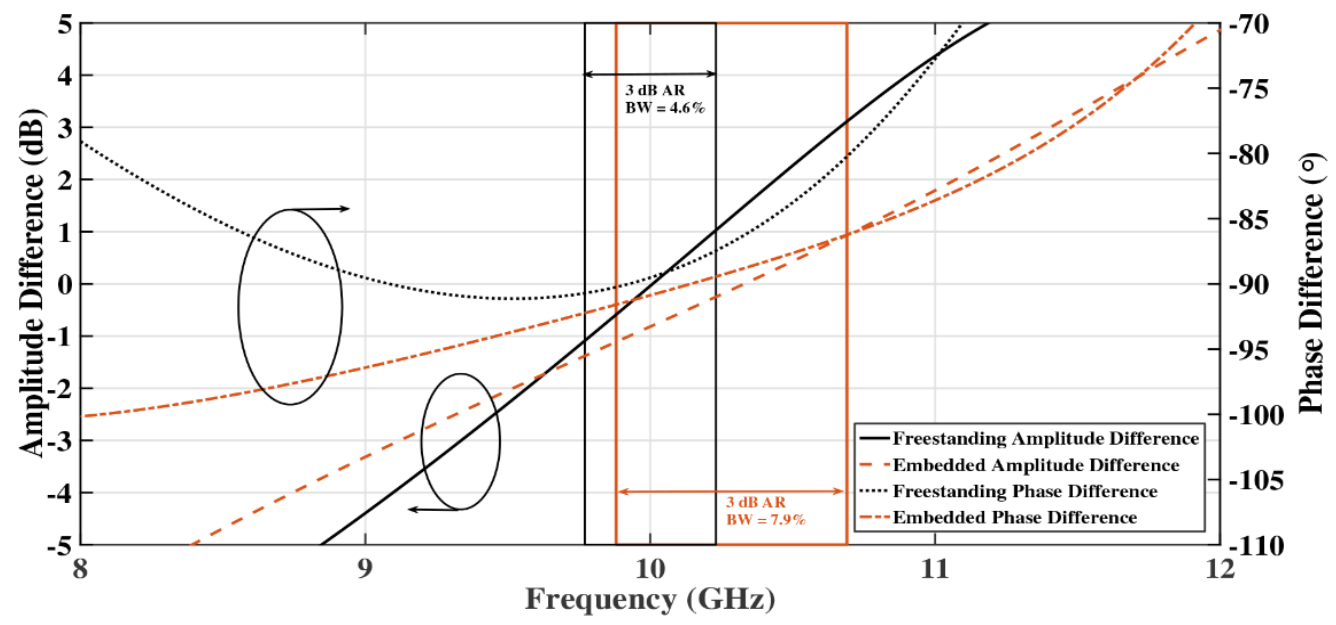

(c) 
Figure 3. (a) Equivalent Circuit Model of the dielectric embedded polarization convertor, (b) comparison of the TE and TM amplitude responses calculated from the ECM and the full wave simulator for the embedded device with PTFE slabs, and the responses calculated from ECM with the PTFE slabs removed.

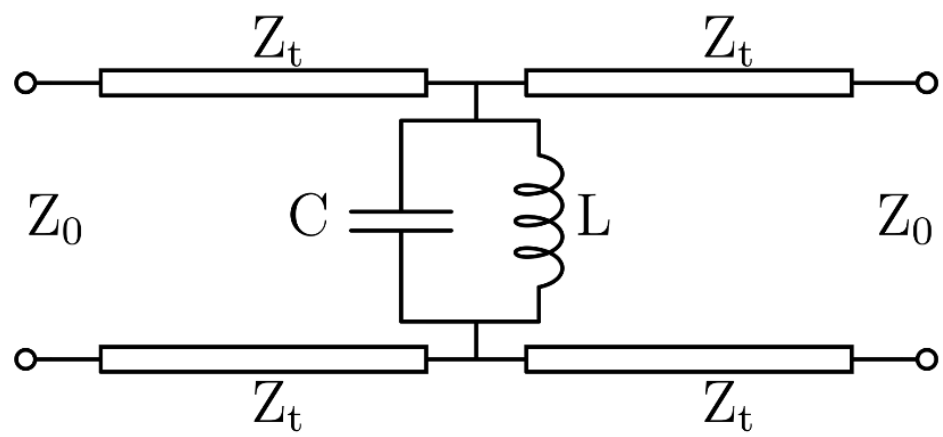

(a)

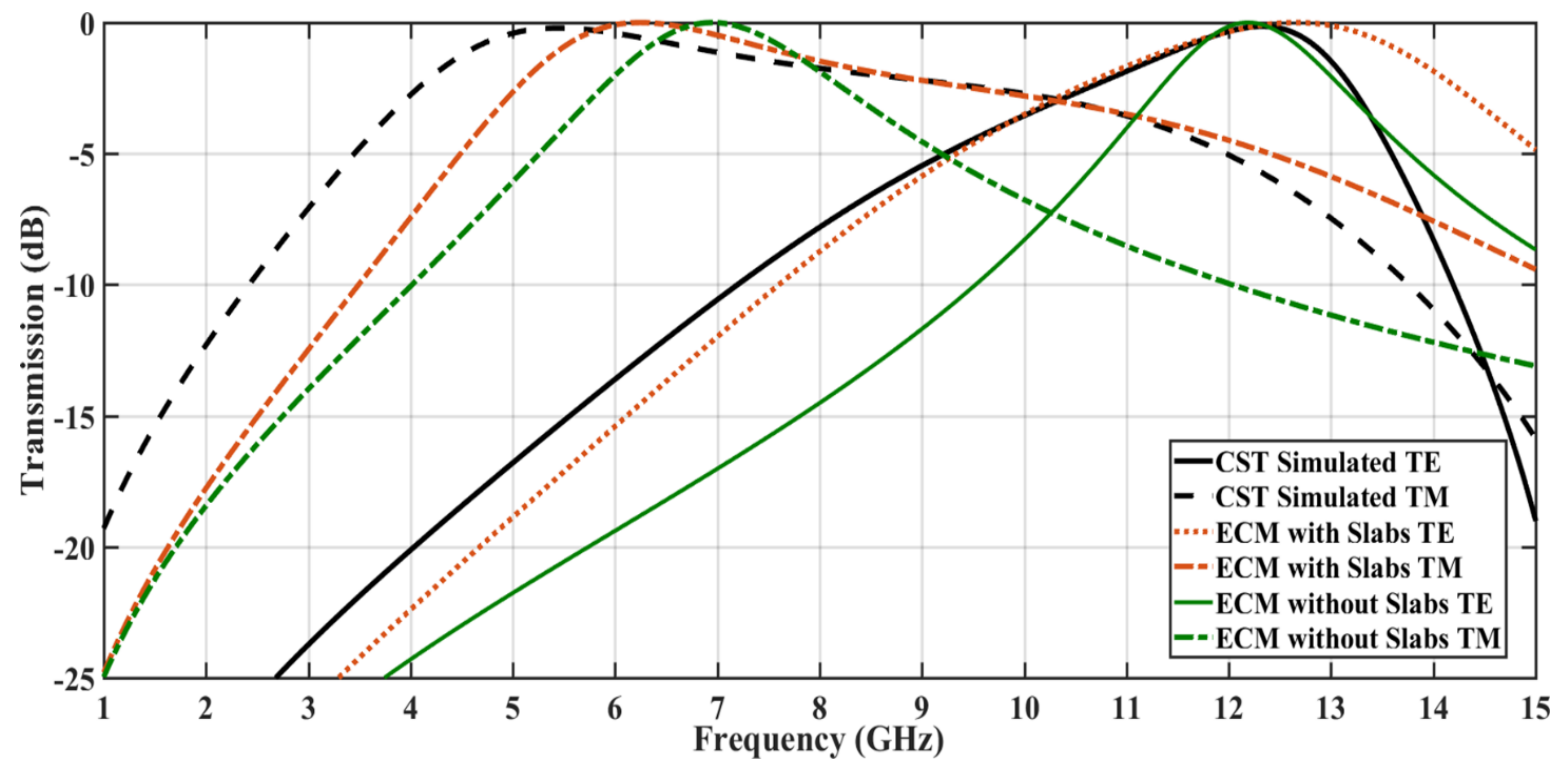

(b) 
Figure 4. Computed axial ratio plots for angles $\theta=0^{\circ}$ to $30^{\circ}$ in the $\varphi=0^{\circ}$ plane for (a) freestanding (b) dielectric embedded polarization converters.

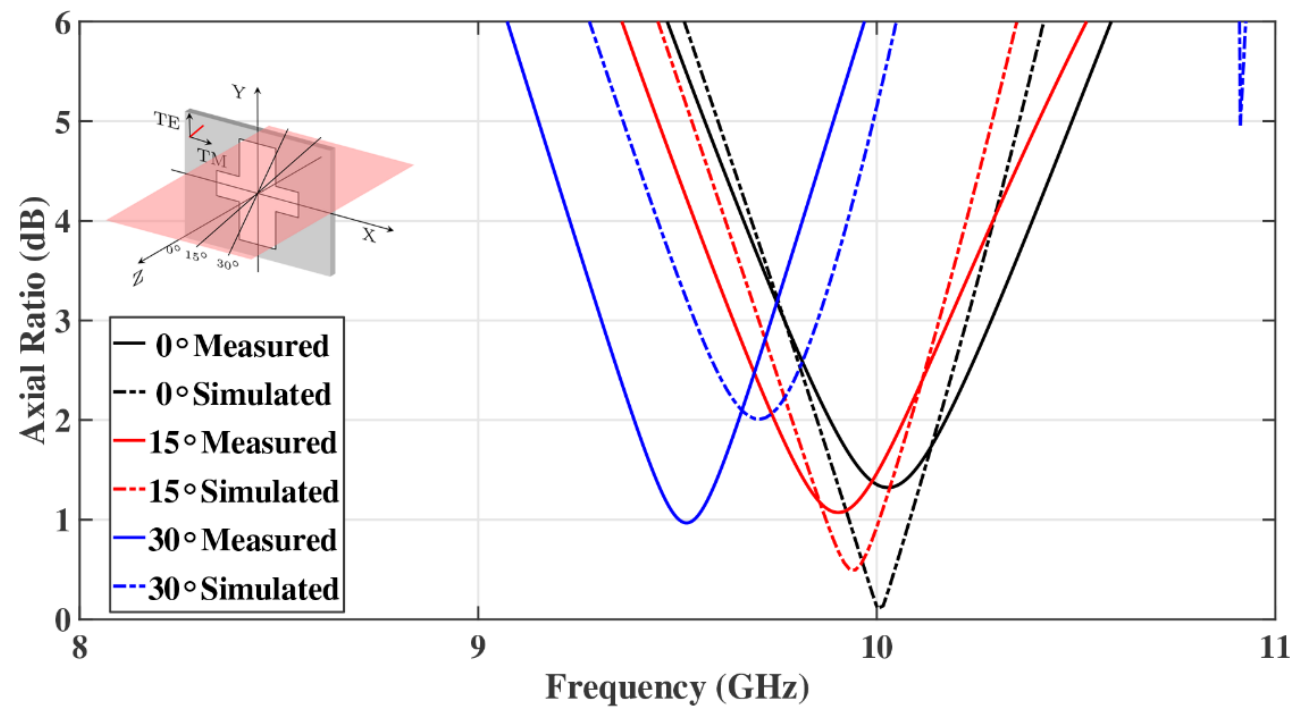

(a)

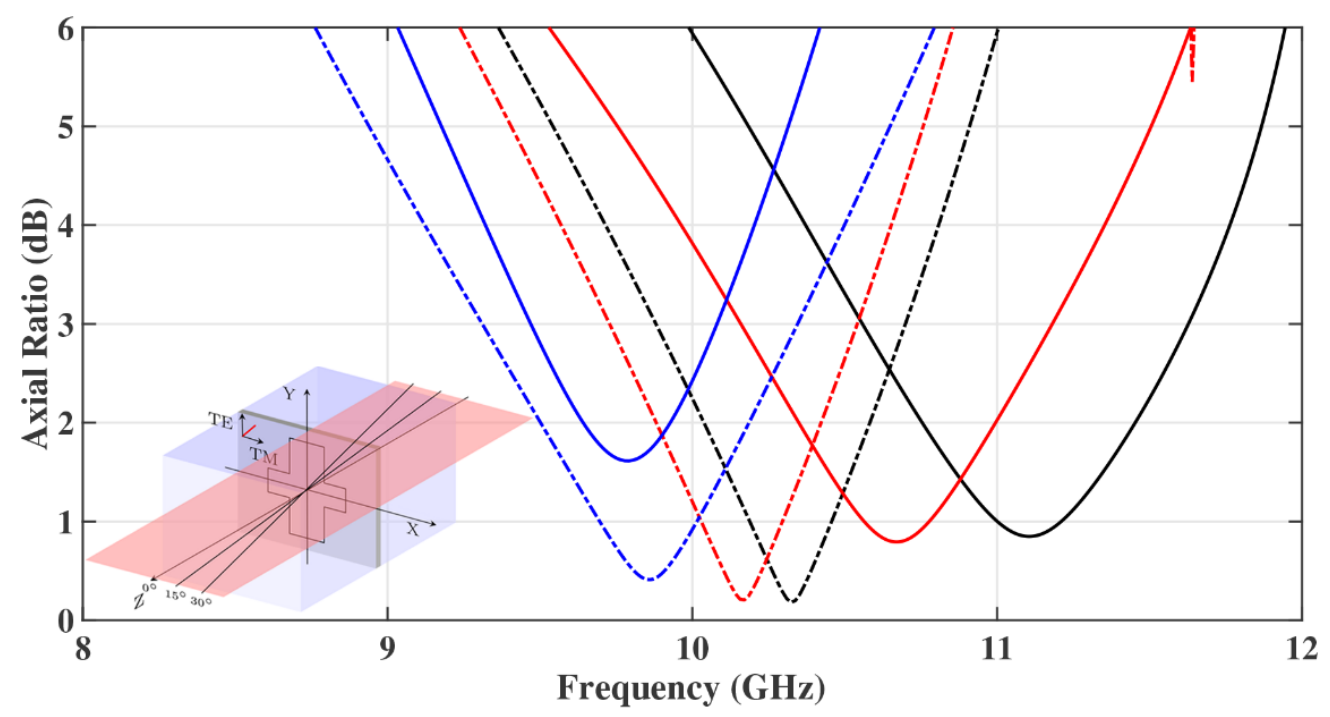

(b) 
Figure 5. Computed axial ratio plots for angles $\theta=0^{\circ}$ to $30^{\circ}$ in the $\varphi=90^{\circ}$ plane for (a) freestanding (b) dielectric embedded polarization converters.

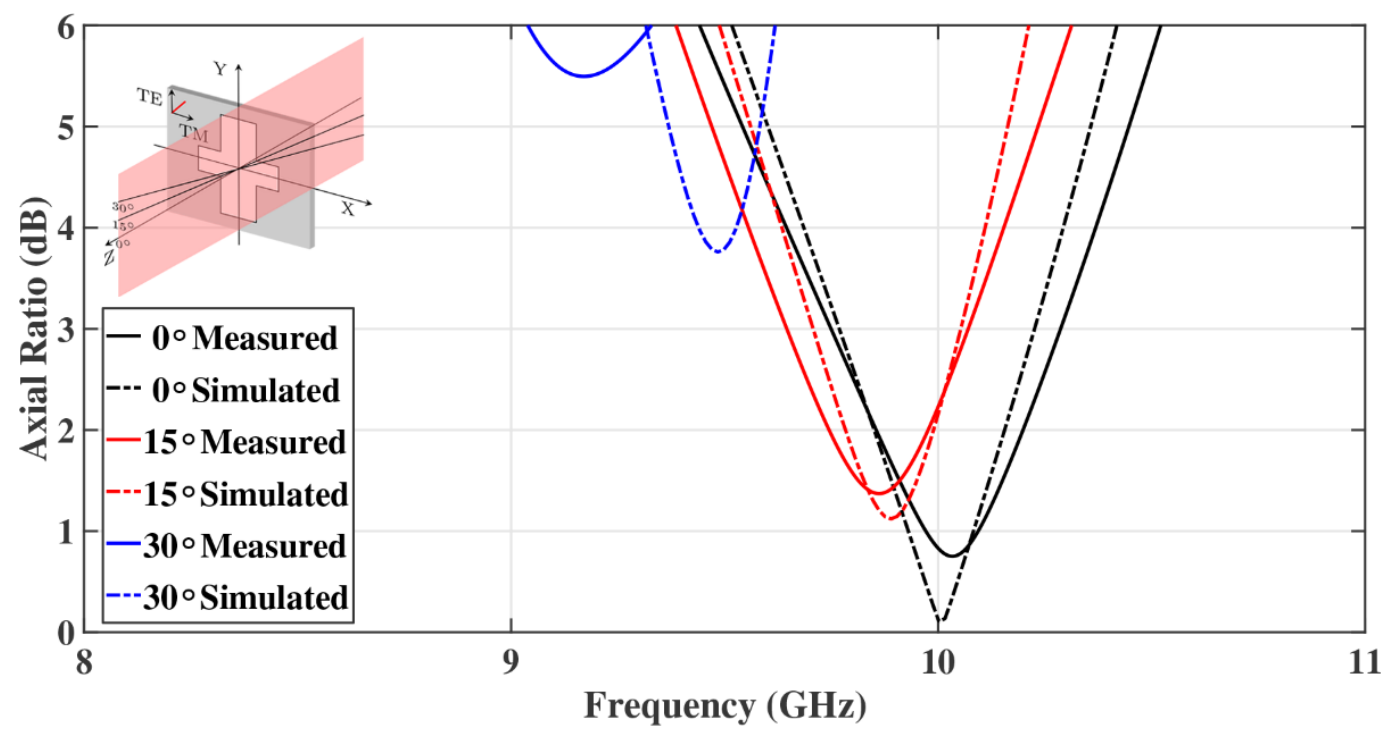

(a)

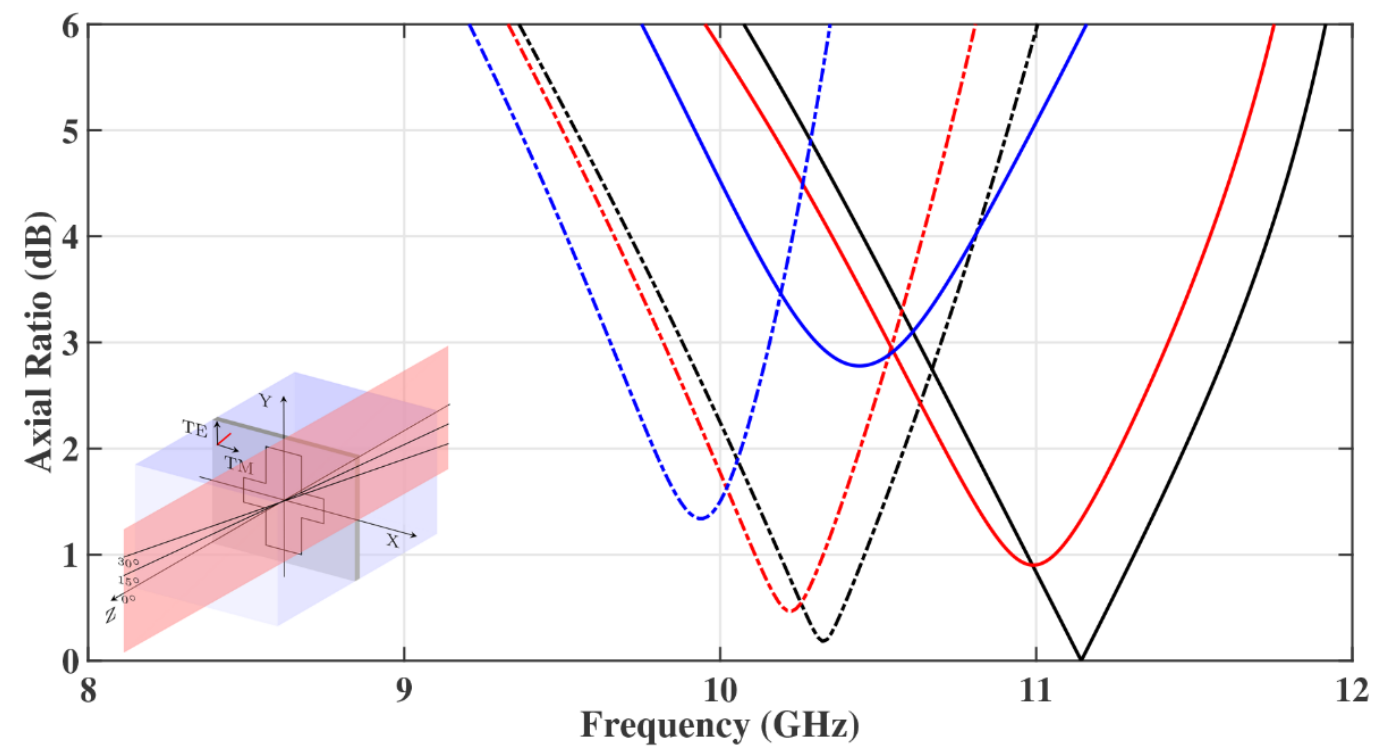

(b) 
Figure 6. Image of the ink jet printed FSS bonded to the surface of a PTFE slab. Inset shows an enlarged image of 4 unit cells.

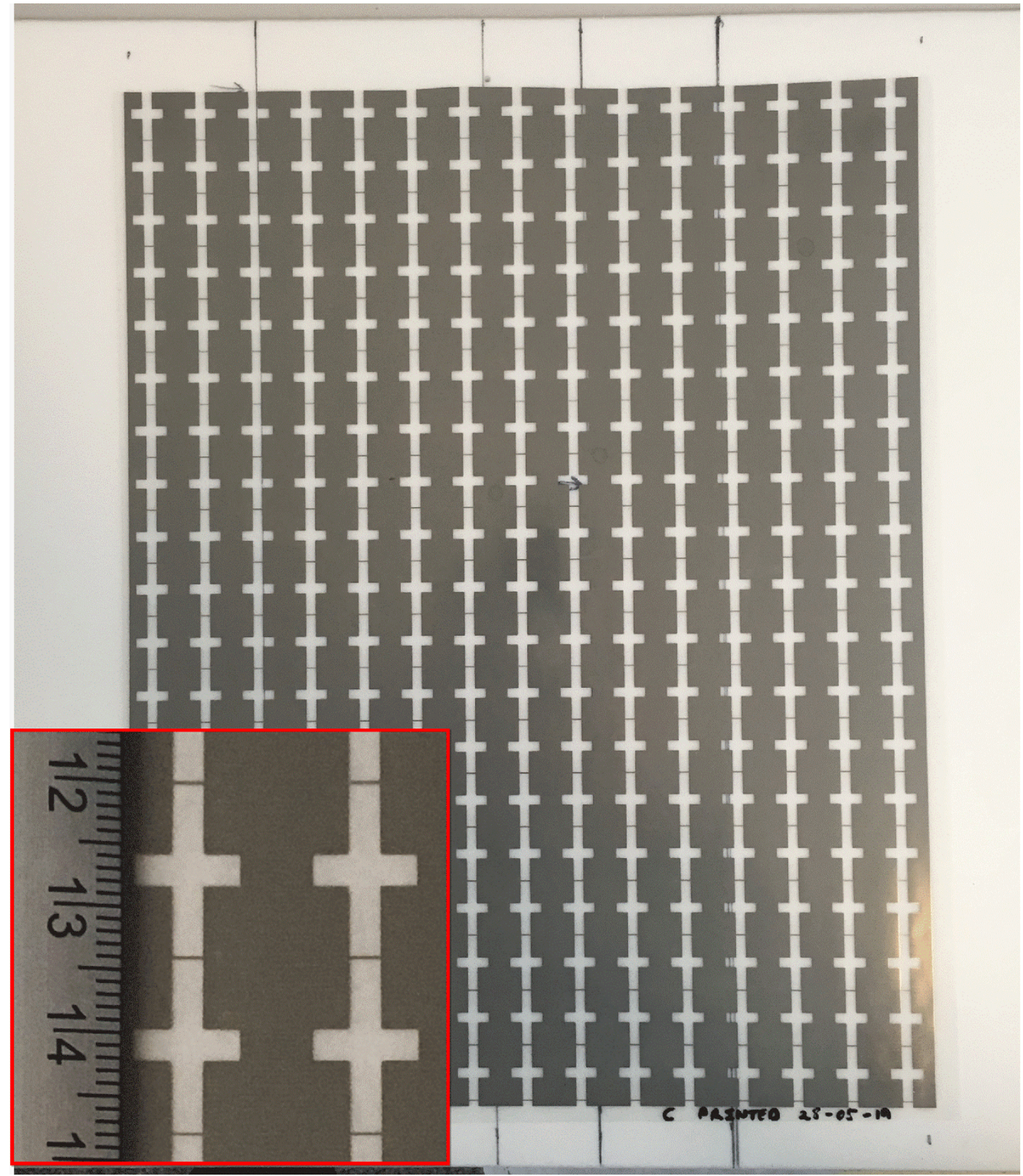


Figure 7. Photograph of the transmission response measurement set-up.

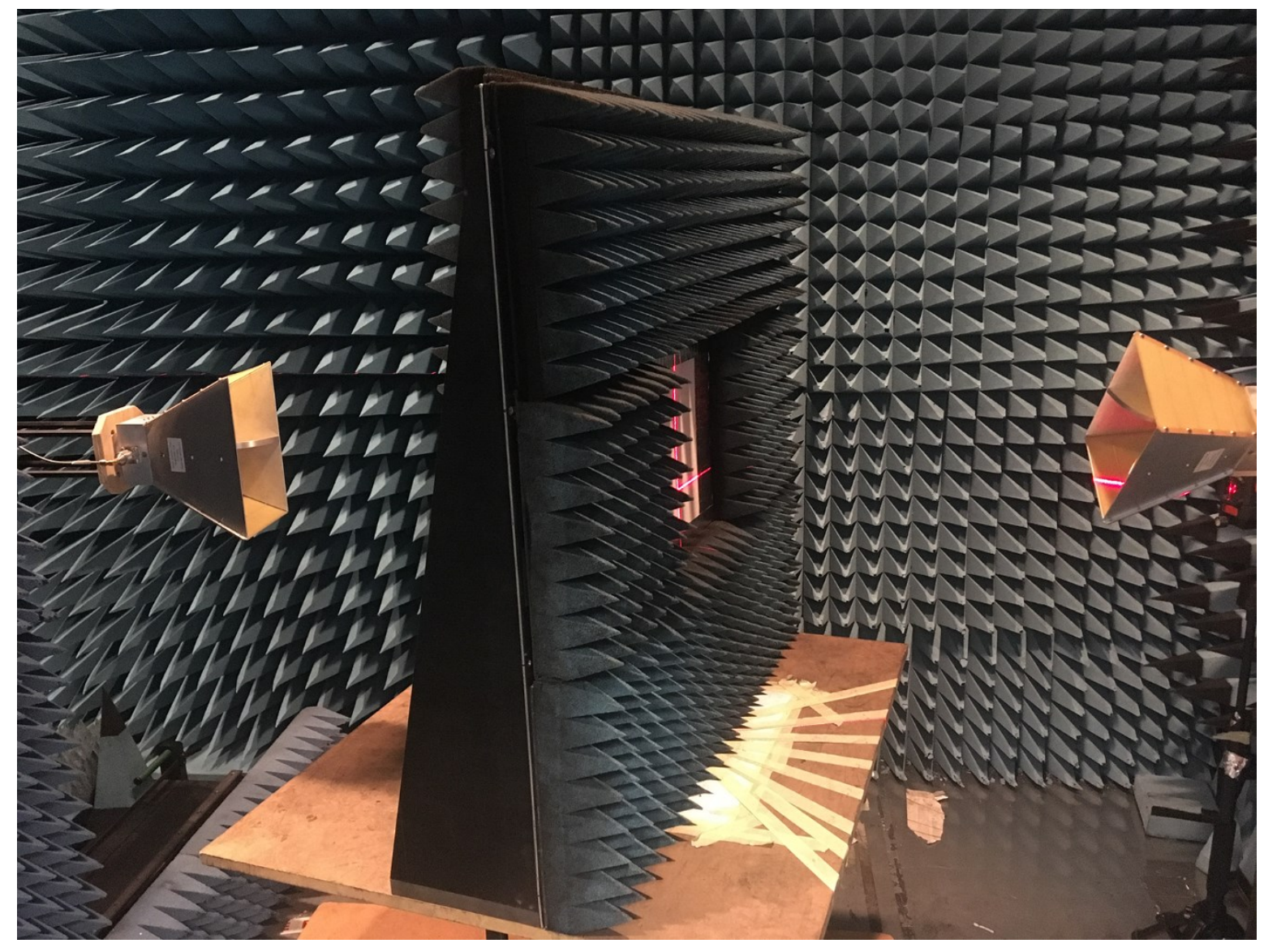


Figure 8. Comparison of measured, (ideal) simulated and simulated with $0.28 \mathrm{~mm}$ air gap in PTFE embedded FSS at normal incidence.

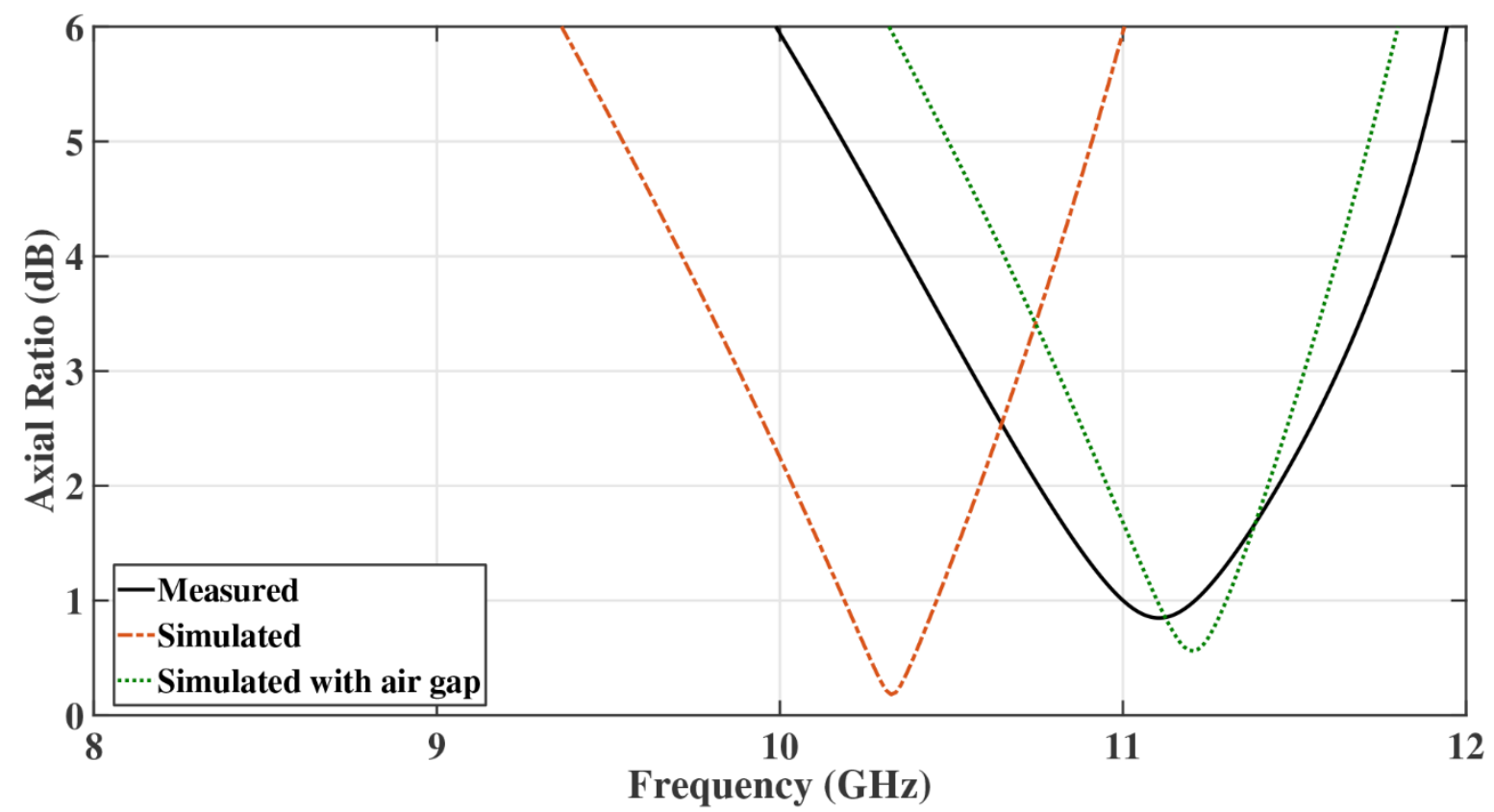

